\title{
PARTICIPAÇÃO SOCIAL NA GESTÃO DE RESÍDUOS SÓLIDOS NA CIDADE DE TEIXEIRA (PB)
}

Ivete Marcelino Campos ${ }^{1}$

João Batista Alves ${ }^{2}$

Resumo: A gestão social participativa e a Educação Ambiental são instrumentos importantes para alcance dos objetivos da Política Nacional de Resíduos Sólidos (PNRS). O presente trabalho descreve a participação social na gestão dos resíduos sólidos (RS) na cidade de Teixeira-PB, para tanto, bairros e ruas significativas foram visitados e realizado levantamento de informações. Nesses setores, diferentes atores sociais foram abordados e questionados sobre problemas socioambientais que incide dos RS. Constatouse que $96 \%$ do lixo doméstico tem descarte inadequado, inexiste incentivo à coleta seletiva e ao sistema de logística reversa. A abordagem educativa sobre RS precisa ser ampliada em todos os setores sociais, pois, Educação Ambiental e a informação são basilares à participação social participativa.

Palavras-chave: Gestão Participativa; Coleta Seletiva; Educação Ambiental.

\footnotetext{
1 Universidade Federal de Campina Grande. E-mail: ivetebio52@gmail.com

2 Universidade Federal de Campina Grande. E-mail: alvesjb@uol.com.br
} 


\section{Introdução}

A natureza provê os recursos necessários à subsistência humana, os quais, através de diferentes técnicas de manejo, são extraídos, explorados e consumidos nas mais diversas atividades produtivas de bens e serviços. Esses recursos, após extração, manejo e consumo geram resíduos, cujo descarte inadequado pode causar danos ao ambiente e à saúde pública (RIBEIRO; MENDES, 2016). O modelo de desenvolvimento em vigor lida, em geral, de forma predatória para gerar aumento de renda e, talvez, bem estar social. Ancora-se no consumo exagerado, cuja consequência é o aumento na geração de resíduos sólidos (RS), em detrimento à preservação ambiental (CORREIO, 2013).

Estratégias para um modelo sustentável de desenvolvimento devem ser pautadas em práticas ambientais que visem reduzir a geração de RS, considerando as variáveis ambiental, social, cultural, econômica, como é observado nos princípios da Política Nacional de Resíduos Sólidos - PNRS e, para tanto, a participação social é condição necessária à sustentabilidade socioambiental e econômica (BRASIL, 2010).

Para Petrus; Pereira Junior (2016), a participação social fortalece a eficiência das ações de políticas públicas, na medida em que visam o benefício da coletividade. Porém, o desafio está em como isto pode ser solidificado no Brasil, pois, mesmo que seja um direito democrático garantido, governos centralizadores, políticos manipuladores e um povo que não reinvidica, permanece a cultura de acomodação e resignação, levando ao fracasso programas e projetos sociais construtivos (LEUZINGER; SILVA, 2017).

Diversas são as possibilidades de participação social na formulação de políticas públicas ambientais, que podem ocorrer em todas as etapas, desde o planejamento, execução, avaliação e monitoramento. A população, por meio da informação, resguarda seu direito em tomadas de decisões, sabendo ser ela a causa e a consequência do próprio modo de desenvolvimento (PEIXOTO, 2015). A gestão social conduz a emancipação.

No caso dos RS e suas implicações, Mesquita Jr. (2007, p. 13), diz que "o conceito de gestão integrada envolve todo um processo e, como tal, deve ser entendido e conduzido de forma integrada, tendo como pano de fundo e razão dos trabalhos". E, para que um plano de gestão integrada de RS produza efeitos positivos o conceito dos R's deve ser levado em consideração: Repensar os hábitos de consumo e comportamentos; Reduzir o consumo; Reaproveitar materiais, de modo a aumentar a vida útil dos produtos; e, Reciclar por meio da coleta seletiva e de logística reversa (PHILIPPI Jr. et al, 2012).

A cidade de Teixeira/PB tem comum com outros meios urbanos em expansão questões ambientais, tais como, falta de infraestrutura, coleta insuficiente e disposição inadequada de RS e falta de saneamento básico (LIMA, 2014). Também comungam das expectativas sociais no tocante ao 
desenvolvimento econômico, pois, à medida que as pessoas procuram realizar essas perspectivas, são induzidas ao consumismo, indiferentes aos resultados negativos que causem ao meio ambiente (CORREIO, 2013).

No diagnóstico ambiental realizado por Alves et. al. (2004) na cidade de Teixeira, foram verificados impactos causados pelo lixo doméstico e outros tipos de resíduos descartados nas ruas e terrenos baldios. Os autores concluíram que esses agravos ambientais poderiam refletir negativamente na qualidade de vida dos moradores, uma vez que o lixo acumulado causa mau cheiro, atrai vetores e animais domésticos, e sendo provocados por eles mesmos.

Tal posicionamento é corroborado por Vilar (2013), para quem a situação dos problemas urbanos ambientais se agrava pela falta de capacitação humana na gestão e no gerenciamento dos RS. No mesmo contexto há a ausência de ações públicas ambientais que visem sanar ou minimizar esses danos. Se, a população não cobra ações efetivas, os governos se omitem e os danos permanecem.

Neste contexto, a Educação Ambiental (EA) antecede processos de conscientização na implantação de plano de gestão integrada, ao gerar reflexões positivas que envolvam e convença, de forma ampla, todos os segmentos da sociedade (BICALHO et al. 2018). A efetividade dos processos em EA se dará se for de maneira continuada e permanente.

Dessas leituras emergiu a pergunta de pesquisa, qual a realidade atual na cidade de Teixeira, em relação aos RS? Existe participação social na gestão dos resíduos sólidos? Existem, em nível local, conscientização e aplicação da EA como instrumento de conscientização nos diferentes setores sociais, em consonância com a PNRS?

Como objetivo da pesquisa levantou-se e descreveu-se a participação social na gestão dos resíduos sólidos na cidade de Teixeira-PB, tendo como parâmetros a PNRS. E, dentro desses parâmetros está a coleta seletiva, a redução, reutilização, reciclagem e o descarte ambientalmente adequado, no qual moradores, comerciantes e educadores têm responsabilidades distintas e inerentes.

Foi verificado o nível de informação de comerciantes locais em relação à logística reversa e ao descarte ambientalmente adequado dos RS comerciais; o comportamento de alunos de ensino médio relação ao descarte dos RS e averiguadas práticas e ações pedagógicas para conscientização ambiental na concepção de ensino formal e geral da população.

Este estudo, por fim, ao realizar as análises e interpretação dos resultados, pretendeu saber os entraves à gestão social participativa na Teixeira - PB e contribuir por reflexões positivas. 


\section{Metodologia}

O presente trabalho foi realizado na Cidade de Teixeira, localizada no Estado da Paraíba, Mesorregião do Sertão Paraibano e Microrregião da Serra do Teixeira. De acordo com o Instituto Brasileiro de Geografia e Estatística IBGE, a população está estimada em 15.191 habitantes, distribuídos numa área territorial de $114 \mathrm{~km}^{2}$. O município apresenta potencial ecoturístico, proporcionado a partir do conjunto de formações geomorfológicas da Serra do Teixeira, com desníveis da ordem de até 500 metros na face voltada para 0 pediplano sertanejo (CORREIA; MOREIRA, 2013). A Figura 1 revela três aspectos do ecoturismo local.
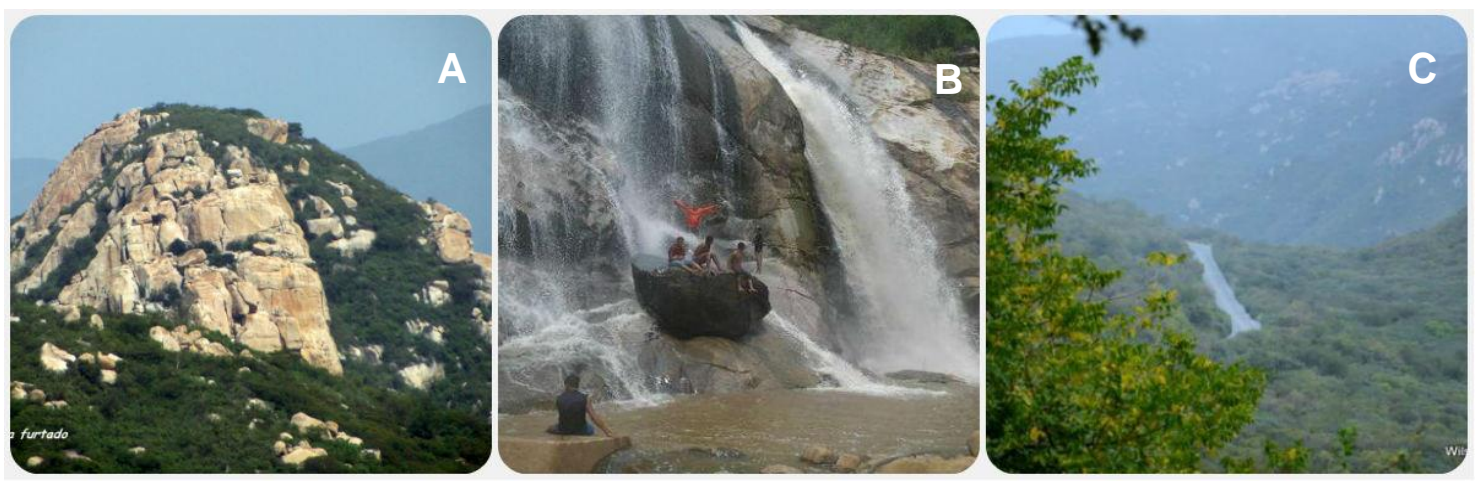

Figura 1: Imagens de pontos ecoturisticos em Teixeira - PB. A) Pedra do Talhado; B) Cachoeira do Espelho; C) Vista panorâmica a partir da Pedra do Tendó. Teixeira-PB, 2018.

Fonte: A) https://www.flickr.com/photos/sonia furtado;

B) https://www.flogao.com.br/turmadoscobras;

C) https://wilsonpjansen.wordpress.com/tag/tendor

Além do potencial ecoturístico a Serra do Teixeira possui biodiversidade faunística e florística, nascentes de pequenos riachos intermitentes e clima ameno. É possível avistar animais como veados, macacos-prego, onça puma, novas espécies de lagartos e borboletas (ICMBIO, 2018).

O Instituto Chico Mendes realizou visitas técnicas na região para avaliar as condições físicas para a criação do Parque Nacional da Serra de Teixeira, que poderá englobar cerca de 10 municípios paraibanos, com predominância do Bioma Caatinga e, numa avaliação inicial, foi considerada área apta (ICMBIO, 2018).

A pesquisa envolveu revisão bibliográfica, visita de campo em 9 bairros da cidade (Centro, Santa Maria, Caipira, Água azul, Nova Teixeira, Vila Feliz, Santo Antonio, Pedra do Galo e Severina do Rego Leite), onde foram aplicados questionários e feitas observações. Foram feitas anotações e registros de imagens.

Foram aplicados 140 questionários, dos quais 100 foram aplicados a moradores maiores de 18 anos, residentes nos domicílios visitados, 20 aplicados aos comerciantes em diferentes atividades comerciais e 12 
professores de uma Escola Estadual de Ensino Médio. Para cada público alvo, foi elaborado um questionário específico, com questões fechadas e de múltiplas escolhas.

Para o cálculo do número de domicílios urbanos a serem entrevistadas, foi estabelecido a partir do número residências em área urbana, utilizando os dados do senso demográfico do IBGE (2010).

Para equacionar o número de visitas a campo,utilizou-se da equação proposta por Rocha (1997), a saber: $\mathrm{N}=3,841 \cdot \mathrm{n} \cdot 0,25 /\left[(0,1)^{2} \cdot(\mathrm{n}-1)+\right.$ $3,841.0,25]$, em que: $\mathrm{N}=$ número de visitas a serem feitas pelo pesquisador; $3,841=$ valor tabelado proveniente do Qui - Quadrado; $0,25=$ variância máxima para um desvio padrão de 0,$5 ; 0,1=$ erro (10\%) escolhido pelo pesquisador; $\mathrm{n}=$ número total de propriedades na unidade considerada.

Considerando que há 2837 domicílios urbanos na cidade de Teixeira (IBGE, 2010) e, usando a fórmula proposta por Rocha (1997), tem-se aproximadamente 92 pessoas responsáveis por domícilio a serem entrevistadas, nesse sentido optou-se por entrevistar 100 domícilios, de forma aleatória.

A distribuição dos questionários foi feita, respectivamente, em razão da quantidade de domicilios por bairro, segundo dados do IBGE (2010), a saber: Centro, 30; Santa Maria, 20; Caipira, 12; Pedra do galo, 9; Águal Azul, 9; Vila Feliz, 6; Santo Antonio 6; Nova Teixeira, 4; e, Severina do Rego Leite, 4.

A coleta de dados deu-se entre os meses de agosto a outubro de 2018. Inicialmente foram averiguadas, quanto à deposição recolhimento e presença de pontos de acúmulo de lixo, a situação das ruas do centro, estendendo-se gradualmente para outras ruas de bairros periféricos. Observou-se, também, a situação quanto à presença de pontos para coleta seletiva.

Ao mesmo tempo, realizou-se aplicação aleatória de questionários junto aos moradores das ruas visitadas e em casas comerciais (mercadinhos, bares, restaurantes, lojas de varejo, etc.), quando foram feitos questionamentos em relação ao modo de descarte e separação seletiva do lixo. Sobre o entendimento da importância da coleta seletiva e que ações integradas entre a comunidade, o comércio e o poder público, poderiam ser implantadas para melhor gestão dos RS na cidade de Teixeira-PB, conforme os preceitos da PNRS.

Num segundo momento foram feitas visitas, em dias alternados, à Escola Estadual de Ensino fundamental Dr. Manoel Dantas e à Escola Estadual de Ensino Médio Sebastião Guedes da Silva, momento em que a pesquisa foi apresentada a 20 professores, nas duas escolas, que contam com 29 e 36 docentes, respectivamente. Sendo que, desses, 12 professores colaboraram com a pesquisa. Foram averiguadas a opinião e ações dos professores quanto aos hábitos de descarte, separação seletiva dos RS e se desenvolvem, no âmbito das respectivas disciplinas, atividades de conscientização sobre a problemática ambiental dos RS, bem como sugestões para atividade futuras. 
A abordagem foi quantitativa e qualitativa, visto que, opiniões e informações podem ser quantificaveis. Usando técnicas estatisticas, buscou-se relacionar as causas e efeitos de um fenômeno social. Em abordagem qualitativa, o ambiente natural e familiar é fonte direta para coleta e descrição de dados (PRODANOV; FREITAS, 2013). Os tipos de abordagens foram completares entre si.

Os dados foram organizados em planilha eletrônica para ordenação, classificação e posterior avaliação por procedimentos de análise de conteúdo via interpretação de respostas. Segundo Campos (2004), fazer análise de conteúdo significa embasá-la com pressupostos teóricos de diversas concepções de mundo e com as situações concretas de seus produtores ou receptores, visualizadas a partir do contexto histórico e social de sua produção e recepção.

No entendimento de Minayo (2002), o tratamento de material coletado conduz à teorização de dados, produzindo confronto entre a abordagem teórica anterior e o que a investigação de campo aporta de singular como contribuição.

\section{Resultados e discussão}

\section{Dos domicílios}

Nas primeiras observações, feitas inicialmente em ruas centrais, foi possível perceber pontos escassos, ou nenhum registro de lixo amontoado em locais inapropriados, como terrenos baldios, calçadas ou monturos, apesar do hábito regular dos moradores que depositam os resíduos domésticos direto em vias públicas. A questão inicial foi relacionada a esse hábito, perguntou-se qual o destino dado normalmente ao lixo doméstico, conforme mostra a Figura 2:

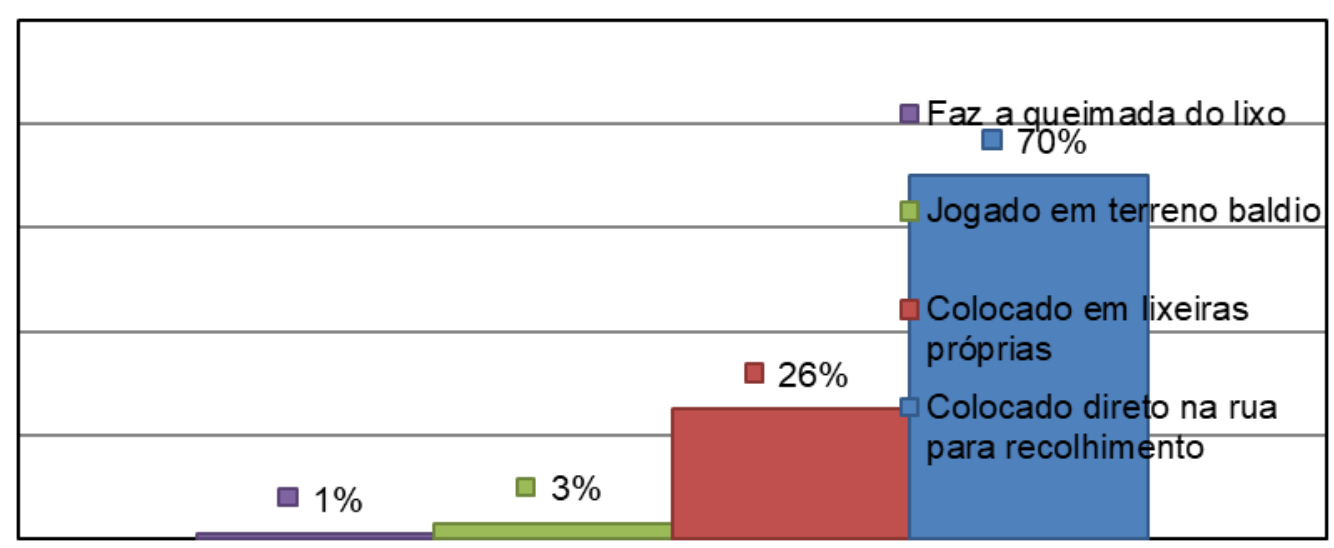

Figura 2: Gráfico representa os hábitos dos residentes em relação quanto à forma de descarte do lixo doméstico. Teixeira-PB. 2018. Fonte: Dados da pesquisa. 
Esse resultado está em conflito com a segunda questão, na qual foi posto: qual era o entendimento em relação ao serviço de limpeza e recolhimento. Nesse sentido, $84 \%$ dos entrevistados consideraram como eficiente, mesmo que admitam fazer descarte inadequado. Situação distinta foi observada em ruas da periferia em que monturos de material de construção são descartados e, por vezes, obstruindo vias públicas. Pode-se considerar o fato pela rápida expansão da área urbana, nos últimos anos, sendo que esse tipo de material é recolhido em menor frequência, como mostra a Figura 3.
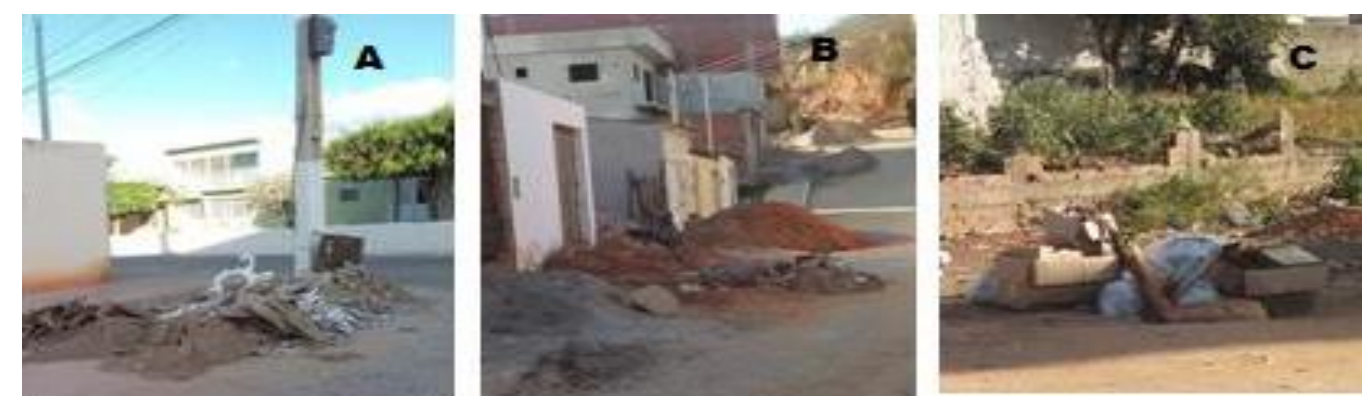

Figura 3: Imagens mostram monturos de resíduos de construção colocados nas ruas do Bairro de Nova Teixeira ( $A, B$ e $C$ ), área periférica que se encontra em franca expansão. Teixeira-PB. 2018. Fonte: Dados da pesquisa.

Os serviços de manejo dos RS incluem, além da coleta doméstica, a limpeza publica e a destinação final, cujas despesas podem impactar em até $20 \%$ os gastos municipais, é o que constata estudos da Associação Brasileira de Empresas de Limpeza Resíduos Especiais - ABRELPE. Ainda segundo o estudo, empresas privadas ganham por tonelada/dia de RS recolhida. Em 2017, no Brasil, foram aplicados, em média, $R \$ 10,37$ por hab./mês em serviços de recolhimento de lixo, totalizando $R \$ 28,5$ bilhões. Os empregos diretos gerados no setor atingiram 337 mil postos de trabalho formal, o que representa fator político e social relevante (ABRELPE, 2017).

A Prefeitura cumpre a tarefa de retirar o lixo "das vistas" da população, que se sente satisfeita pela aparente limpeza. Ficou implícito o desacordo entre o desejo de ter a cidade limpa e a consciência de que a menor geração de resíduos com coleta seletiva são ações benéficas ao meio ambiente, questão anuída por $100 \%$ dos respondentes. Entre polêmicas e dificuldades, falta de recursos financeiros, os entraves políticos, há muito dificultam a inovação de modelos mais adequados e eficazes de limpeza urbana (JACOBI et. al., 2006).

Embora todos os moradores considerem importante fazer a separação seletiva, $49 \%$ declararam não fazê-la, $12 \%$ às vezes e apenas $39 \%$ fazem o manejo de forma adequada (Figura 4). 


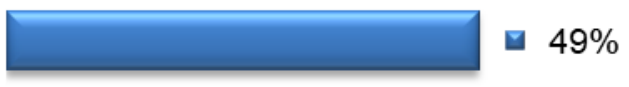

- $39 \%$

Figura 4: Questões referentes à coleta seletiva, aspecto percentual quanto ao habito de separar o lixo seco do molhado. Teixeira-PB. 2018. Fonte: Dados da pesquisa.

Não há indicação de incentivo no sentido de formalizar a coleta seletiva como meio de inclusão socioeconômica, fato reforçado pelo desconhecimento dos moradores sobre pontos de coleta seletiva nas ruas, confirmado por $78 \%$ entrevistados.

A população mostrou-se ciente dos problemas que o descarte inadequado dos RS gera ao mostrarem coerência respondendo os últimos questionamentos sobre a importância da coleta seletiva e que ações poderiam ser feitas no sentido de melhor gerenciamento e manejo dos RS (Figura 5).

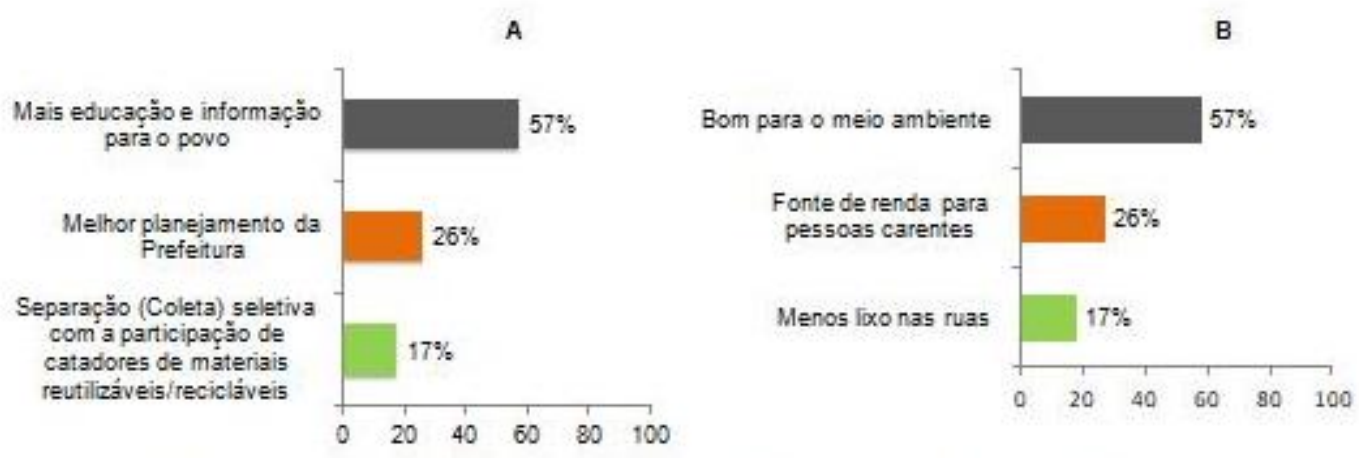

Figura 5: Representações gráficas relacionam dois questionamentos: A) que ação imediata poderia trazer melhorias na gestão dos resíduos; e, B) que benefícios imediatos esta ação produziria. Teixeira-PB. 2018. Fonte: Dados da pesquisa.

Os resultados demonstram que, embora tenha muito a se fazer no sentido de ajuste à gestão dos RS na cidade de Teixeira, principalmente quanto à destinação final, pois é feita em lixão a céu aberto. Pelos resultados pode-se inferir que a população tem ciência dos danos ambientais que decorre do manejo inadequado.

Percebeu-se ausência de atuações necessárias para o alcance dos objetivos da PNRS, sendo que os planos de RS em nível municipal são importantes instrumentos. Neles devem constar programas e ações de 
Educação Ambiental, voltadas a não geração, redução, reutilização, coleta seletiva e reciclagem. Por outro lado, deve haver à participação de cooperativas e associações de catadores. São ações que promovem a abertura de novos mercados, gera emprego, renda, inclusão social e diminui os impactos ambientais provocados pela disposição inadequada dos resíduos (BRASIL, 2010).

Sabe-se que existe valor econômico embutido no lixo e, a sociedade ao acompanhar como ocorre na prática o desenvolvimento do planejamento e da gestão dos RS, torna-se ferramenta imprescindível à implantação de políticas públicas voltadas para a gestão dos resíduos (SOUSA; CAMPOS; OLIVEIRA, 2016).

É premente a necessidade de empenho político para adequação à PNRS, pois como consta no Manual de Boas Práticas no Planejamento (ABRELPE, 2013), ao abordar a gestão dos RS, deve-se considerar integrar os diferentes atores sociais no planejamento, sem os quais não será construído um bom plano.

\section{Do comércio}

Em relação à pesquisa feita nas casas comerciais, foi notada certa dificuldade em obter respostas. A movimentação no comércio e a pressa dos entrevistados podem ter influenciado nas respostas. Percebeu-se que 0 conhecimento e a aplicação do sistema da logística reversa são insuficientes. Alia-se a esse fato o pouco cuidado no tocante a questão dos RS, sendo o comércio importante gerador de material com potencial de reciclagem e reaproveitamento.

Neste tipo de atividade, as ruas também são o local comum de deposição para o lixo, $70 \%$ dos entrevistados assim age. O restante, afirmou fazer a separação seletiva dos RS para reciclagem. Do total de material informado, papelão e plástico, corresponde a $75 \%$ dos resíduos gerados.

Tratando-se de saber qual a destinação dada aos de produtos vencidos que surgem no comércio, $45 \%$ dos comerciantes assumem que os destinam ao lixo comum, o percentual dos que devolve ao fabricante foi de $40 \%$. O restante assume por vezes fazer uma ou a outra prática.

Embora os dados apresentem percentual menor de comerciantes (45\%) afirmando sempre descartar produtos vencidos diretamente na rua, não há indicação de entendimento adequado por parte daqueles que afirmaram sempre devolver ou às vezes o fazem. Em relação à responsabilidade compartilhada pelo ciclo de vida dos produtos, sobre a qual, o art. $3^{\circ}$, XII da PNRS menciona que é "um conjunto de ações, procedimentos e meios destinados a viabilizar a coleta e a restituição dos resíduos sólidos ao setor empresarial, para reaproveitamento [...], ou destinação final ambientalmente 
adequada; [...]" (BRASIL, 2010). Observou-se que pouco se tem feito em Teixeira-PB.

Presume-se que a adequação à legislação é iniciativa dos revendedores atacadistas (distribuidores), mais passiveis de sofrerem sansões legais. Dessa forma, é inerente a desinformação em relação às atribuições da política de logística reversa em que se faz necessário o conhecimento dos estabelecimentos comerciais, visto que fazem a ponte entre o consumo inicial e - passo final, que é responsabilidade de quem produz (VELÁZQUEZ; MARCON, 2017).

\section{Da Escola}

Inicialmente enfrentou-se resistência à pesquisa, pois se sabe as dificuldades enfrentadas por professores do ensino público, que trabalham em condições inseguras, submetidos a contratos temporários, fato constatado na visita à escola de ensino fundamental, onde os professores não se motivaram a colaborar. Atenta-se ao fato sobre o qual a Lei de Diretrizes e Bases da Educação - LDB, atribui aos Municípios ofertar o ensino fundamental em colaboração com os Estados, que tem como prioridade o Ensino Médio (BRASIL, 2017). Sendo parcos recursos humanos e físicos da referida escola.

Sobre esta realidade, na qual parte do quadro docente abordado mostrou-se desmotivado, no que diz respeito a apresentar ações educativas sobre RS, considerou-se analisar criticamente, no contexto escolar, diversos aspectos que colaboram para tal desgaste, pois, como qualquer outra instituição social, está permeada por interesses e poderes nem sempre explícitos ou fáceis de ser identificados (SCHULTZ; CAMPOS, 2018).

Nesta experiência, os 12 docentes que aceitaram responder ao questionário, são do Ensino Médio, todos efetivos, mostraram-se atualizados com as questões ambientais e dispostos a colaborar com informações para a pesquisa, bem como sugerindo atividades em EA que venham a ser incluídas no Projeto Político Pedagógico da escola.

Os resultados referentes ao entendimento dos professores sobre hábitos dos alunos, quanto ao modo de descarte ambientalmente correto dos resíduos, mostram a necessidade de melhor orientação, pois 50\% dos respondentes disseram que nem sempre os alunos o fazem, $42 \%$ disseram não fazer e, em contra partida, somente $8 \%$ disseram que fazem. Em complemento a esta questão, foi perguntado aos professores se os alunos sabiam fazer a separação seletiva. Em resposta, $25 \%$ dos professores não sabem dizer, $33 \%$ disseram que eles não sabem e $42 \%$ referiram que os alunos sabiam fazer a separação seletiva (Figura 6). 


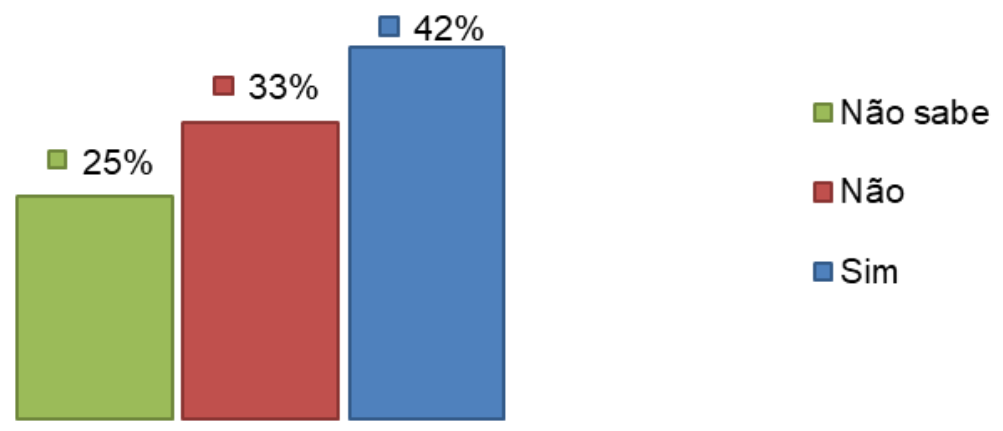

Figura 6 - O gráfico apresenta a opinião dos professores sobre se os alunos sabem fazer a separação seletiva dos RS. Teixeira-PB. 2018. Fonte: Dados da pesquisa.

Pelas imprecisões nas respostas, pode-se denotar que os docentes não desejassem conflitar, mostrando a realidade de forma negativa. Os mesmos que, anteriormente, conjecturaram sobre a forma incorreta como os alunos descartam o lixo, 58\% observaram que existem coletores próprios à disposição.

Proporção significativa (83\%) revelou não ter dificuldades em abordar o tema em suas disciplinas, e a esse respeito pelo menos $50 \%$ já aplicaram alguma atividade relacionada às questões ambientais. Percebeu-se um distanciamento entre $\mathrm{o}$ saber docente e a realidade cultural na ambiência escolar, onde é necessário abordar a EA demonstrando sua importância no contexto ambiental, e sensibilizando os alunos para que se tornem agentes transformadores, tendo condições de modificar a realidade ao seu redor (OLIVEIRA; SANTOS, 2018).

EA é colocada como uma dimensão importante dentro da educação e da atividade intencional da prática social. $O$ art. 5 complementa: "A Educação Ambiental não é atividade neutra, pois envolvem valores, interesses, visão de mundo e, desse modo, deve assumir na prática educativa, de forma articulada e interdependente, as suas dimensões política e pedagógica" (BRASIL, 2012, p. 2).

Diante de tantas questões que afligem a saúde do planeta, educar para o meio ambiente é um desafio para todas as esferas da sociedade. A escola exerce papel primordial nesse desafio para, além de superar o descaso proferido constantemente sobre as políticas dedicadas a educação no Brasil, promovam diálogos que ajustem as relações divergentes entre o que pauta a escola e o que compete aos órgãos responsáveis pelas políticas educacionais (SCHULTZ; CAMPOS, 2018).

O último questionamento colocado aos docentes foi que propostas pedagógicas, em relação aos RS, poderiam envolver os alunos com as questões relacionadas aos RS em suas respectivas disciplinas. Nas respostas, 10 professores de diferentes disciplinas ressaltaram que a discussão deve ser constante no ambiente escolar, incentivando a participação em projetos sobre a 
problemática ambiental que o descarte inadequado provoca. Foi enfatizada a importância de promover aulas em contato com natureza, sensibilizar através da percepção ambiental.

A temática ambiental na escola pode ser favorecida pela criação de cenários que envolvam a formação do pensamento critico dos alunos para que se percebam agentes transformadores do meio natural. Enxergando a poluição sintomática de atividades mal gerenciadas, quanto proporcionando 0 entendimento sobre medidas mitigadoras e de preservação (ROCHA; VIVEIRO, 2018; OLIVEIRA et. al., 2018).

Institui-se a importância da Educação Ambiental como uma prática interdisciplinar, conforme preconiza a Lei $n^{0}$ 9795/99, objetivando a compreensão integrada do meio ambiente em suas múltiplas e complexas relações a fim de fomentar novas práticas sociais (BRASIL, 1999).

Por fim foi solicitado aos docentes citarem, na disciplina que ministram se já desenvolveram atividades educacionais relacionadas aos RS. Em seguida que sugerissem temas para projetos que poderiam incluir no Projeto Político Pedagógico (PPP) da escola. O Quadro 1 relaciona as atividades já desenvolvidas e sugeridas, de acordo com as disciplinas ministradas pelos 12 professores entrevistados.

Quadro 1: Atividades que já foram desenvolvidas e atividades sugeridas para inclusão no Projeto Político Pedagógico da escola de ensino médio. Teixeira-PB. 2018.

\begin{tabular}{|c|c|c|}
\hline Disciplina & Atividades desenvolvidas & Atividades sugeridas \\
\hline Matemática & $\begin{array}{l}\text { Reciclagem de materiais } \\
\text { para construção de jogos } \\
\text { didáticos }\end{array}$ & $\begin{array}{l}\text { Projetos para criação de horta na escola; } \\
\text { de compostagem/ reciclagem/arborização. }\end{array}$ \\
\hline Biologia & $\begin{array}{l}\text { Construção de coletores } \\
\text { com materiais recicláveis }\end{array}$ & $\begin{array}{l}\text { Aulas de campo ver a realidade do lixo em } \\
\text { lugares públicos }\end{array}$ \\
\hline Português & Não & $\begin{array}{l}\text { Orientações sobre a captação/ } \\
\text { reaproveitamento de água das chuvas }\end{array}$ \\
\hline Biologia & $\begin{array}{lll}\begin{array}{l}\text { Projeto } \\
\text { reciclagem }\end{array} & \text { 3R's } & \text { sobre } \\
\end{array}$ & Trabalhar projetos sobre reciclagem \\
\hline Historia/Filosofia & $\begin{array}{l}\text { Aula sobre coleta dos } \\
\text { resíduos sólidos }\end{array}$ & $\begin{array}{l}\text { Realizar projetos sobre conservação } \\
\text { ambiental }\end{array}$ \\
\hline Historia/Filosofia & Projeto de reciclagem & $\begin{array}{l}\text { Incentivar a coleta seletiva, a reciclagem } \\
\text { na escola, palestras em Educação } \\
\text { Ambiental }\end{array}$ \\
\hline Matemática & Não & $\begin{array}{l}\text { Projetos sobre poluição por causa do } \\
\text { descarte do lixo }\end{array}$ \\
\hline Matemática & Não & $\begin{array}{l}\text { Incentivar o uso de coletores para } \\
\text { separação dos resíduos sólidos }\end{array}$ \\
\hline Português & Não & $\begin{array}{l}\text { Palestras, projetos com a participação dos } \\
\text { alunos e pesquisa de campo. }\end{array}$ \\
\hline Química & Comentários e discussão & $\begin{array}{l}\text { Mostrar e reconhecer a importância do } \\
\text { tema }\end{array}$ \\
\hline Biologia & Não & $\begin{array}{l}\text { Inserir conteúdos relacionados ao } \\
\text { descarte do lixo em todas as disciplinas }\end{array}$ \\
\hline Português & Não & Apresentar conteúdos interdisciplinares \\
\hline
\end{tabular}

Fonte: Elaborada pelos autores.

Revbea, São Paulo, V. 14, № 4: 323-339, 2019. 
A temática ambiental foi considerada importante no desenvolvimento de conteúdos que contribuam para a compreensão e enfrentamento das questões ambientais mediante postura participativa e colaborativa de toda comunidade escolar. Para tanto, que a EA seja trabalhada de acordo com as Diretrizes Curriculares Nacionais para a Educação Ambiental - DCNEA, (BRASIL, 2012).

Pode-se considerar a interdisciplinaridade o meio capaz de estreitar relações complexas e analisar interações dinâmicas, tais quais as socioambientais e relacionadas aos RS, quando apresentadas de maneira difusa. Ensina-se que o meio ambiente deve ser preservado, no entanto, carece de atividades de impacto adequadas e que conduzam os jovens a um papel mais participativo futuramente, sensíveis às causas ambientais de acordo com a realidade comunitária.

Mesmo com as dificuldades e desafios a superar, no que tange o ensino de ED em escolas públicas, como falta de material didático, maior compreensão e colaboração por parte da comunidade escolar, a maioria dos professores mostrou capacidade e ciência das suas responsabilidades socioeducativas.

Elaborar um PPP exige engajamento coletivo da comunidade escolar, porque ele é norteador da organização do trabalho que fundamenta os princípios da escola democrática, pública e gratuita e é a partir dele que os sujeitos conduzem, reestruturam e avaliam seu funcionamento (CARBONELL, 2002; GUEDES; SILVA; GARCIA, 2017).

A todo o momento e em qualquer ambiência social cabe a discussão sobre a responsabilidade com a preservação ambiental. A escola é terreno fértil e ideal para disseminar valores e comportamentos ambientalmente responsáveis. É necessário ensinar aos jovens hoje, para depois cobrar dos mesmos quando adultos.

\section{Considerações finais}

A presente pesquisa seguiu a metodologia proposta e, com os dados obtidos e analisados, descreveu como ocorre a gestão participativa dos RS se estava em acordo com a PNRS, na Cidade de Teixeira-PB envolvendo três setores importantes da sociedade: a população, o comércio e o ensino formal.

Foi constatado que em $70 \%$ dos domicílios o descarte do lixo é feito nas ruas, sem prévio manejo pela separação seletiva, o que contribuiria com 0 aspecto ambiental e com o trabalho de catadores de recicláveis, pois, menos lixo iria para o lixão e os catadores teriam material com qualidade. Esse foi o entendimento de $100 \%$ dos moradores, mesmo dos que agem de maneira inadequada.

O que de fato ocorre é que em Teixeira não tem coleta seletiva, não há ações da Prefeitura. Nesse sentido, parte da população faz separação do lixo seco do molhado de livre e espontânea vontade. Nesses aspectos a população 
concorda que mais informação e educação no contexto social contribuiriam para integrar sociedade e governo municipal, exigindo deste a efetivação de medidas mitigadoras dos efeitos negativos da má gestão dos RS.

A solução das questões socioambientais parte necessariamente da adesão à gestão participativa, precedido por amplo processo educativo e informativo. Educar e informar significa, sobretudo, promover a cidadania, onde conhecer e exerce direitos em relação à qualidade ambiental, resulte em políticas voltadas ao benefício da coletividade.

Em relação à atividade comercial na cidade, viu-se que 0 aproveitamento de materiais reutilizáveis e recicláveis está na ordem de $30 \%$. Evidenciou-se o desperdício de um setor que é importante gerador e, necessita empenho na observância do sistema de logística reversa. Vale ressaltar que é de toda a sociedade a responsabilidade pelo ciclo de vida dos produtos de consumo. Devolvendo-os às cadeias produtivas, com a reciclagem poupam-se recursos naturais e os danos ambientais serão reduzidos.

No aspecto de ensino formal, com a desmotivação apresentada por parte dos professores do ensino fundamental, constatou-se que a abordagem de temas ambientais é insuficiente nas práticas pedagógicas. Porém, mesmo com as precariedades e dificuldades enfrentadas no ensino público, os professores entrevistados mostraram preparo e conhecimento para incluir atividades que fomente a sensibilização sobre temas sociais relevantes na comunidade escolar.

Por fim, observou-se que em Teixeira-PB, existe desacordo com a PNRS. Não há gestão participativa, na qual sociedade e poder público interajam, assumido responsabilidades e buscando soluções ativa e integrada, no que dizer respeito aos de RS. Espera-se que os resultados de pesquisa possam contribuir para reflexões construtivas sobre questões de natureza socioambiental, própria do modo de vida da sociedade e que podem ser enfrentadas com EA e conscientização.

\section{Referências}

ABRELPE - ASSOCIAÇÃO BRASILEIRA DE EMPRESAS DE LIMPEZA PÚBLICA E RESÍDUOS ESPECIAIS. Panorama dos Resíduos Sólidos no Brasil, 2017. Disponível em: <https://belasites.com.br/clientes/abrelpe/site/wpcontent/uploads/2018/09/SITE grappa panoramaAbrelpe ago v4.pdf.. .

Acesso em: 09 de Out. de 2018.

ABRELPE - ASSOCIAÇÃO BRASILEIRA DE EMPRESAS DE LIMPEZA PÚBLICA E RESÍDUOS ESPECIAIS. Resíduos sólidos: manual de boas práticas no planejamento. 2013. Disponível em: <http://a3p.jbri.gov.br/pdf /ABRELPE\%20Manual\%20BOAS\%20PRATICAS\%202013.pdf>. Acesso em: 09 de Out. 2018. 
ALVES, J. B. et al. Diagnóstico ambiental de ruas e bairros da cidade de Teixeira, PB. Revista Árvore, Viçosa, v. 28, n. 5, p. 755-764, 2004.

BICALHO, M. L. et. al. Gestão socioambiental de resíduos sólidos urbanos em Lavras-MG. Gestão \& Regionalidade, v. 34, n.100, p. 183 - 199, 2018.

BRASIL. Presidência da República. Lei no 12.305, de 10 de agosto de 2010. Institui a Política Nacional de Resíduos Sólidos; altera a Lei 9.605, de 12 de fevereiro de 1988; e dá outras providências.

BRASIL. Lei no 9.795 de 27 de abril de 1999. Dispõe sobre a Educação Ambiental, institui a Política Nacional de Educação Ambiental e dá outras providências. Brasília: Congresso Nacional, 1999.

BRASIL. Ministério da Educação. Diretrizes Curriculares Nacionais para a Educação Ambiental Parecer CNE/CP ํo 14/2012 aprovado em 6 de junho de 2012.

CAMPOS, C.J.G. Método de análise de conteúdo: ferramenta para a análise de dados qualitativos no campo da saúde. Revista Brasileira de Enfermagem, n. 57(5): 611-4. Brasília - DF, 2004.

CARBONELL, J. A aventura de inovar: a mudança da escola. Porto Alegre: ARTMED, 2002. $120 \mathrm{p}$.

CORREIA, S. C. C.; MOREIRA, E. Campesinato do município de Teixeira na Paraíba: resistência e formas de recriação camponesa. Pegada - A Revista da Geografia e do Trabalho, v.14, n.1, p. 112-138, 2013.

CORREIO, E. R. S. A gestão do "lixo" e suas implicações na construção de cidades sustentáveis. Revista Eletrônica do Curso de Direito da UFSM, v, 8, n. 2, 311-332, 2013.

GUEDES, J. V.; SILVA, A. M. F.; GARCIA, L. T. S.; Projeto político-pedagógico na perspectiva da educação em direitos humanos: um ensaio teórico. Revista Brasileira de Estudos Pedagógicos. Brasília, v. 98, n. 250, p.580-595, set./dez. 2017.

IBGE - INSTITUTO BRASILEIRO DE GEOGRAFIA E ESTATÍSTICA. Cidades. Teixeira/Paraíba. 2018. Disponível em: < https://cidades.ibge.gov.br/ brasil/pb/teixeira/panorama>. Acesso em: 20 de Mar 2018

ICMBIO - INSTITUTO CHICO MENDES PARA A BIODIVERSIDADE. Dia Nacional da caatinga é comemorado neste sábado. Disponível em: < http://www.icmbio.gov.br/portal/ultimas-noticias/20-geral/9596-dia-nacional-dacaatinga-e-comemorado-neste-sabado>. Acesso em: 29 de Out. 2018.

LEUZINGER, M. D.; SILVA, S. T. O princípio da participação e a criação e gestão das áreas protegidas na perspectiva do direito ambiental global. Revista de Direito Internacional. Brasília, v. 14. n 3. p. $134-146$. 2017. 
LIMA, V. Análise da qualidade ambiental urbana: o exemplo de Osvaldo Cruz/SP. Revista Geografia em Questão. V. 07, n.02, p.29-42, 2014.

MEDEIROS, M. C. S.; RIBEIRO, M. C. M; FERREIRA, C. M. A. Meio ambiente e Educação Ambiental nas escolas públicas. Âmbito Jurídico, Rio Grande, XIV, n. 92, set 2011.

MESQUITA Jr., J. M. Gestão Integrada de resíduos sólidos. Rio de Janeiro: Ibam, 2007, 40 p. Disponível em: < http://www.ibam.org.br/media/arquivos lestudos/01-girs mdl 1.pdf>. Acesso em: $27 \mathrm{de} \mathrm{fev.} 2019$.

MINAYO, M. C. S. (org.). Pesquisa Social: Teoria, método e criatividade. Editora Vozes, Petrópolis, 2002. 80 p.

JACOBI, P.; VIVEIROS, M. Da vanguarda à apatia, com muitas suspeitas no meio do caminho - Gestão de resíduos sólidos domiciliares em São Paulo entre 1989 e 2004. In. JACOBI, P. (Org.). Gestão compartilhada dos resíduos sólidos no Brasil: inovação com inclusão social. São Paulo-SP: ANNABLUME, 2006. 163 p.

OLIVEIRA, N. et. al. Percepção de estudantes em meio ambiente sobre os problemas ambientais, Alcântara-MA. Revista Educação Ambiental em Ação. Número 64, Ano XVII. Junho-Agosto. 2018.

OLIVEIRA, T. M. L.; SANTOS, A. Uso de atividades lúdicas para o ensino aprendizagem de Educação Ambiental no município de Mamanguape-PB. Revista Educação Ambiental em ação, n. 63, ano XVI, Março/Junho. 2018.

PEIXOTO, L A. G. Abordagens e perspectivas de participação social no monitoramento de políticas públicas. Revista de Políticas Públicas. São Luís. v. 19, n.2, p. 403-410, jul/dez. 2015.

PETRUS, J. K. B.; PEREIRA JÚNIOR, M. V. A influência da participação social para o desenvolvimento local. Polis Revista Latino-americana. n. 44, 2016.

PHILIPPI Jr. A., et al. Gestão integrada de resíduos sólidos. In: JARDIM, A.; YOSHIDA, C.; FILHO, J. V. M. (Orgs.). Política nacional, gestão e gerenciamento de resíduos sólidos. Barueri-SP: Ed. MANOLE, 2012. 732 p.

PRODANOV, C. C.; FREITAS E. C. Metodologia do trabalho científico: Métodos e Técnicas da Pesquisa e do Trabalho Acadêmico. $2^{\underline{a}}$ ed. Novo Hamburgo-RS. FEEVALE, 2013. 277 p.

RIBEIRO, B. M. G.; MENDES, C. A. B. Situação dos resíduos sólidos urbanos no Brasil: desafios da sustentabilidade ambiental. $7^{0}$ Fórum internacional de resíduos sólidos, Porto Alegre, 2016.

ROCHA, J. S. M. Manual de projetos ambientais. Santa Maria: Imprensa Universitária, 1997. 423p. 
ROCHA, P. N.; VIVEIRO, A. A. Projeto jardim vertical - uma articulação escola-comunidade protagonizada pelos estudantes. In: GEHLEN, B. A.; TREVISAN, J.; BARBOSA, S. (Orgs.). Destaques do I Prêmio Nacional Educação Ambiental em Ação / Novo Hamburgo, 2018. 261 p.

SCHULTZ, J. P.; CAMPOS, M. A. T. Reflexões acerca da complexidade no processo educativo: a Educação Ambiental escolar em questão. Revista Educação Ambiental em Ação, Paraná. Número 64, Ano XVII. JunhoAgosto/2018.

SOUSA. C. A. F.; CAMPOS, J. C.; OLIVEIRA, B. M. Panorama do gerenciamento dos resíduos sólidos no Brasil e no Nordeste após a implementação do PNRS. Revista Científica ANAP Brasil, v. 9, n. 15, 2016.

VELÁZQUEZ, V. H. T.; MARCON, V. T. B. Aspectos relevantes da logística reversa na Política Nacional de Resíduos Sólidos. Revista Direito Ambiental e Sociedade, v. 7, n. 3, p. 201-229, 2017.

VIEIRA, P. L.; BELTRAME, L. T. C. Educação Ambiental: a resposta para o problema de resíduos sólidos urbanos. 8ํㅜㅇum Internacional de Resíduos Sólidos, Curitiba. 2017.

VILAR, J. W. C. O plano de gestão integrada de resíduos sólidos do baixo São Francisco sergipano: avanços e desafios. Geonordeste, Ano XXIV, n.2, 2013. 